\title{
Case report: Compound heterozygous mutations in AP4M1 gene identified in a Chinese infant with Infantile Spasms and Global developmental delay
}

\section{Lily Zhang}

Xiangya Hospital Central South University

Xingbing Jin

Xiangya Hospital Central South University

\section{Yaqin Wang}

Central South University Third Xiangya Hospital

Yan He ( $\sim 191798047 @ q q . c o m$ )

Children's Hospital of Nanjing Medical university https://orcid.org/0000-0002-0404-0857

Haoyu Li

Xiangya Hospital Central South University

\section{Case report}

Keywords: AP4M1, Whole-exome sequencing, Developmental delay, Infantile Spasms, Case report

Posted Date: January 25th, 2021

DOl: https://doi.org/10.21203/rs.3.rs-151765/v1

License: (c) (i) This work is licensed under a Creative Commons Attribution 4.0 International License. Read Full License 


\section{Abstract}

Background: Adaptor protein complex-4 (AP-4), a heterotetrameric protein complex, plays an important role in vesicle trafficking in neurons. Mutations in genes affecting different subunits of AP-4, including $A P 4 B 1, A P 4 E 1, A P 4 S 1$, and $A P 4 M 1$, have been recently associated with spastic tetraplegia, developmental delay and intellectual disability (ID).

Case presentation: We report on a Chinese patient with infantile spasms, infantile hypotonia and global developmental delay. Exome sequencing showed compound heterozygous mutations in $A P 4 M 1$ (c.19A>G, p.I7V and c.137C>T, p.P46L).

Conclusions: This is the first case of biallelic missense variants lay on the region encoding LH domain, which is important for membrane trafficking via protein-protein and intramolecular binding specificities. Our study expands the molecular spectrum associated with AP-4 deficiency syndrome, and reviews the clinical features of reported patients with AP4M1 mutations.

\section{Background}

The Adaptor related protein complex4(AP4M1) gene encodes a subunit of the heterotetrameric adaptor protein complex 4(AP4), which is composed of two large chains beta-4 (AP4B1) and epsilon-4 (AP4E1), a medium mu-4 chain (AP4M1) and a small sigma-4 chain (AP4S1)[1]. AP-4 complex-mediated trafficking plays a crucial role in brain development and function. AP-4 deficiency syndrome, also known as AP-4 associated hereditary spastic paraplegia (HSP), is a group of neurodegenerative disorders characterized by developmental delay, severe intellectual disability, spasticity and microcephaly of essentially postnatal onset. Early-onset hypotonia evolves into progressive lower-extremity spasticity[2,3]. Here we present a case of compound heterozygous $A P 4 M 1$ mutations in a Chinese girl with infantile spasms, infantile hypotonia and global developmental delay, and review the clinical features of patients with AP4M1 mutations.

\section{Case Presentation}

The infant was the first child born to the non-consanguineous Chinese parents (Figure1a), She was a fullterm newborn by cesarean delivery with no perinatal brain injury, hypoxia, or infection the central nervous system. The parents declared no family history of epilepsy or other neurological conditions.

Developmental delay was noticed when she was unable to track, hold up her head and sit independently at six months. She started to have infantile spasms when she was 7 months, with the symptom of clustered flexor spasm of upper limbs, eyes rolling and head nodding. Interictal EEG revealed hypsarrhythmia. The seizure frequency was up to 15 times per day. Multiple anti-epileptic drugs including sodium valproate, topamax and prednisone were given to the patient, but seizures were not well controlled with a frequency of about 10 times a day. Low-dose adrenocorticotropic hormone (ACTH) therapy was given combined with sodium valproate and topamax at the age of 8 
months, but with no improvement of seizures control indicated by EEG after 14 days of treatment. We then replaced the ACTH with sabril and continued the treatment, the seizures were finally under control after three days. On the examination at 10 months, she could hold up her head and sit independently for a few minutes, hypotonia and limbs weakness were observed. Body height and head circumference were in normal range. Blood routine examination showed thrombocytopenia, which may relate to the use of several antiepileptic drugs.

Blood and urine screenings for genetic metabolic disorders were negative. Developmental Screen Test (DST) at 7 months showed the developmental quotient (DQ) was below 60 and the mental index (MI) was less than 46, scores less than 70 on DQ and Ml are considered abnormal. Brain MRI of 3.0 Tesla at 7 months indicated delayed myelination and nonspecific loss of bilateral frontal-parietal lobes white matter (Figure1b). Interictal EEG at 7 months showed hypsarrhythmia consisting of bilateral high-amplitude irregular slow waves mixed with multiple focal spikes or poly spikes in the interictal period (Figure1c).

Whole-exome sequencing (WES) was performed in the proband and her parents. The proband's Trio-WES identified compound heterozygous mutations in $A P 4 M 1$ (c.19A>G, p.17V and c.137C>T, p.P46L)

(Figure1a). The two missense variants are highly conserved (GERP++, phastCons46way primates) and located at the longin-like (LH) domain, and are predicted to be damaging by several prediction tools (SIFT, PolyPhen2, and Mutation Taster). Segregation analysis by Sanger sequencing confirmed that the compound heterozygous state of these variants is segregating with the phenotype (Figure2a).

\section{Discussion And Conclusion}

AP complexes are crucial for vesicular trafficking from the trans-Golgi network to the plasma membrane[4,5]. Defects of either the B1, E1, M1 or S1 subunit of AP4 are characterized by the combination of infantile hypotonia, developmental delay, intellectual disability, early-onset spastic paraplegia, and thinning of the corpus callosum on brain MRI[6]. Autosomal recessive HSP due to pathogenic variants in $A P 4 M 1$ is a rare neurodevelopmental disorder. Very few patients and families have been described in the literatures. To date, only 22 patients from ten families with pathogenic AP4M1 variants have been reported (figure2b) $[7,8,2,9,6,1,10-12]$. We summarized the clinical features of patients with AP4M1 mutations in table1. Among these pathogenic variants, most of these variants are positioned within a region encoding the mu homology domain (MHD), an essential proteinprotein interaction module. Only the biallelic frameshift mutation lays on a position encoding LH domain located in the $\mathrm{N}$-terminal part of the protein, causing premature stop codons and truncating the protein before MHD[10]. Truncation mediated decay of the entire mRNA, is likely to cause complete loss of AP4M1 function. Patients with biallelic loss-of-function mutations of AP4M1 have been described with severe infantile hypotonia and diffuse white matter loss on brain MRI[7-9,1]. It is speculated that the AP4M1 defect results in abnormal cycling of glutamate receptors, mimicking glutamate mediated perinatal white matter injury[7]. 
Here we report the compound heterozygous mutations in $A P 4 M 1$ (c. $19 A>G$ and c.137C $>T$ ) on a patient with infantile spasms, infantile hypotonia and developmental delay. This is the first case of biallelic missense variants lay on the region encoding LH domain, which is important for membrane trafficking via protein-protein and intramolecular binding specificities. It was reported that the missense mutations generally result in a milder phenotype compared to the homozygous truncated mutations have been identified[1]. Due to a residual function of the AP4M1 gene, the affected individual in this study showed a milder presentation, with normal occipitofrontal circumference and no diffuse white matter involvement on her brain MRI. Phenotypic heterogeneity may be related to the different protein domains affected. Our study expands the molecular spectrum associated with AP-4 deficiency syndrome. Further studies are needed to investigate the role of AP-4 in brain development and neurotransmission.

\section{Abbreviations}

AP4M1: Adaptor related protein complex4; EEG: Electroencephalogram; MRI: Magnetic resonance imaging; WES: Whole exome sequencing; DST: Developmental Screen Test; DQ: Developmental quotient;

\section{Declarations}

\section{Ethics approval and consent to participate}

The study protocol was approved by the Ethic Committee of the Xiangya Hospital of Central South University. Written informed consent was obtained from the patients' father.

\section{Consent for publication}

Written informed consent for publication was obtained from the participants or their guardians.

\section{Availability of data and materials}

All data generated or analyzed during this study are included in this published article.

\section{Competing interests}

The authors declare that they have no competing interests.

\section{Funding}

This work was supported by grants from the Natural Science Foundation of Hunan Province, China (grant number 2020JJ4854), Research project of Chenzhou first people's Hospital (grant number N2019-020). The funding body had no influence in the design of the study and collection, analysis, and interpretation of data and in writing the manuscript.

\section{Authors' contributions}


XBJ and LLZ designed the study, monitored the family investigation, collected clinic data, drafted and revised the manuscript. YQW contributed to exome sequencing, Sanger sequencing. YH and HYL contributed to sample collection and genetic counselling. All authors read and approved the final manuscript.

\section{Acknowledgements}

Gratitude is extended to the subject family for their cooperation and participation.

\section{References}

1. Bettencourt C, Salpietro V, Efthymiou S, Chelban V, Hughes D, Pittman AM, Federoff M, Bourinaris T, Spilioti M, Deretzi G, Kalantzakou T, Houlden H, Singleton AB, Xiromerisiou G (2017) Genotypephenotype correlations and expansion of the molecular spectrum of AP4M1-related hereditary spastic paraplegia. Orphanet J Rare Dis 12 (1):172. doi:10.1186/s13023-017-0721-2

2. Roubertie A, Hieu N, Roux CJ, Leboucq N, Manes G, Charif M, Echenne B, Goizet C, Guissart C, Meyer P, Marelli C, Rivier F, Burglen L, Horvath R, Hamel CP, Lenaers G (2018) AP4 deficiency: A novel form of neurodegeneration with brain iron accumulation? Neurol Genet 4 (1):e217. doi:10.1212/nxg.0000000000000217

3. Moreno-De-Luca A, Helmers SL, Mao H, Burns TG, Melton AM, Schmidt KR, Fernhoff PM, Ledbetter DH, Martin CL (2011) Adaptor protein complex-4 (AP-4) deficiency causes a novel autosomal recessive cerebral palsy syndrome with microcephaly and intellectual disability. J Med Genet 48 (2):141-144. doi:10.1136/jmg.2010.082263

4. Abou Jamra R, Philippe O, Raas-Rothschild A, Eck SH, Graf E, Buchert R, Borck G, Ekici A, Brockschmidt FF, Nöthen MM, Munnich A, Strom TM, Reis A, Colleaux L (2011) Adaptor protein complex 4 deficiency causes severe autosomal-recessive intellectual disability, progressive spastic paraplegia, shy character, and short stature. Am J Hum Genet 88 (6):788-795. doi:10.1016/j.ajhg.2011.04.019

5. Ebrahimi-Fakhari D, Teinert J, Behne R, Wimmer M, D'Amore A, Eberhardt K, Brechmann B, Ziegler M, Jensen DM, Nagabhyrava P, Geisel G, Carmody E, Shamshad U, Dies KA, Yuskaitis CJ, Salussolia CL, Ebrahimi-Fakhari D, Pearson TS, Saffari A, Ziegler A, Kölker S, Volkmann J, Wiesener A, Bearden DR, Lakhani S, Segal D, Udwadia-Hegde A, Martinuzzi A, Hirst J, Perlman S, Takiyama Y, Xiromerisiou G, Vill K, Walker WO, Shukla A, Dubey Gupta R, Dahl N, Aksoy A, Verhelst H, Delgado MR, Kremlikova Pourova R, Sadek AA, Elkhateeb NM, Blumkin L, Brea-Fernández AJ, Dacruz-Álvarez D, Smol T, Ghoumid J, Miguel D, Heine C, Schlump JU, Langen H, Baets J, Bulk S, Darvish H, Bakhtiari S, Kruer MC, Lim-Melia E, Aydinli N, Alanay Y, El-Rashidy O, Nampoothiri S, Patel C, Beetz C, Bauer P, Yoon G, Guillot M, Miller SP, Bourinaris T, Houlden H, Robelin L, Anheim M, Alamri AS, Mahmoud AAH, Inaloo S, Habibzadeh P, Faghihi MA, Jansen AC, Brock S, Roubertie A, Darras BT, Agrawal PB, Santorelli FM, Gleeson J, Zaki MS, Sheikh SI, Bennett JT, Sahin M (2020) Defining the clinical, molecular and 
imaging spectrum of adaptor protein complex 4-associated hereditary spastic paraplegia. Brain 143 (10):2929-2944. doi:10.1093/brain/awz307

6. Hebbar M, Shukla A, Nampoothiri S, Bielas S, Girisha KM (2019) Locus and allelic heterogeneity in five families with hereditary spastic paraplegia. J Hum Genet 64 (1):17-21. doi:10.1038/s10038-0180523-y

7. Verkerk AJ, Schot R, Dumee B, Schellekens K, Swagemakers S, Bertoli-Avella AM, Lequin MH, Dudink J, Govaert P, van Zwol AL, Hirst J, Wessels MW, Catsman-Berrevoets C, Verheijen FW, de Graaff E, de Coo IF, Kros JM, Willemsen R, Willems PJ, van der Spek PJ, Mancini GM (2009) Mutation in the AP4M1 gene provides a model for neuroaxonal injury in cerebral palsy. Am J Hum Genet 85 (1):4052. doi:10.1016/j.ajhg.2009.06.004

8. Tüysüz B, Bilguvar K, Koçer N, Yalçınkaya C, Çağlayan O, Gül E, Sahin S, Çomu S, Günel M (2014) Autosomal recessive spastic tetraplegia caused by AP4M1 and AP4B1 gene mutation: expansion of the facial and neuroimaging features. Am J Med Genet A 164a (7):1677-1685. doi:10.1002/ajmg.a.36514

9. Jameel M, Klar J, Tariq M, Moawia A, Altaf Malik N, Seema Waseem S, Abdullah U, Naeem Khan T, Raininko R, Baig SM, Dahl N (2014) A novel AP4M1 mutation in autosomal recessive cerebral palsy syndrome and clinical expansion of AP-4 deficiency. BMC Med Genet 15:133. doi:10.1186/s12881014-0133-2

10. Langouët M, Siquier-Pernet K, Sanquer S, Bole-Feysot C, Nitschke P, Boddaert N, Munnich A, Mancini GM, Barouki R, Amiel J, Colleaux L (2015) Contiguous mutation syndrome in the era of highthroughput sequencing. Mol Genet Genomic Med 3 (3):215-220. doi:10.1002/mgg3.134

11. Najmabadi $H, H u H$, Garshasbi M, Zemojtel T, Abedini SS, Chen W, Hosseini M, Behjati F, Haas S, Jamali P, Zecha A, Mohseni M, Püttmann L, Vahid LN, Jensen C, Moheb LA, Bienek M, Larti F, Mueller I, Weissmann R, Darvish H, Wrogemann K, Hadavi V, Lipkowitz B, Esmaeeli-Nieh S, Wieczorek D, Kariminejad R, Firouzabadi SG, Cohen M, Fattahi Z, Rost I, Mojahedi F, Hertzberg C, Dehghan A, Rajab A, Banavandi MJ, Hoffer J, Falah M, Musante L, Kalscheuer V, Ullmann R, Kuss AW, Tzschach A, Kahrizi K, Ropers HH (2011) Deep sequencing reveals 50 novel genes for recessive cognitive disorders. Nature 478 (7367):57-63. doi:10.1038/nature10423

12. Duerinckx S, Verhelst H, Perazzolo C, David P, Desmyter L, Pirson I, Abramowicz M (2017) Severe congenital microcephaly with AP4M1 mutation, a case report. BMC Med Genet 18 (1):48. doi:10.1186/s12881-017-0412-9

\section{Tables}

Due to technical limitations, table 1 is only available as a download in the Supplemental Files section.

\section{Figures}


a

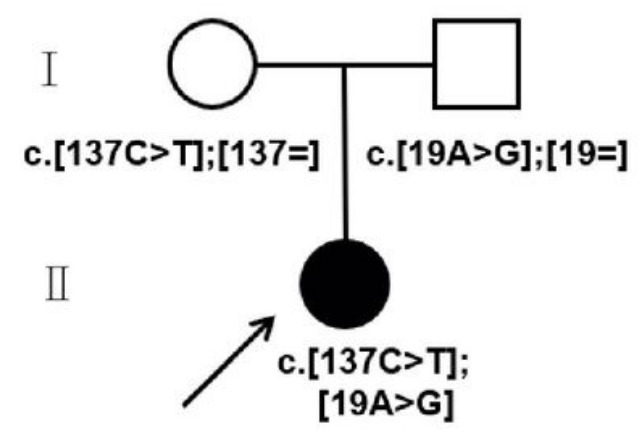

\section{b}

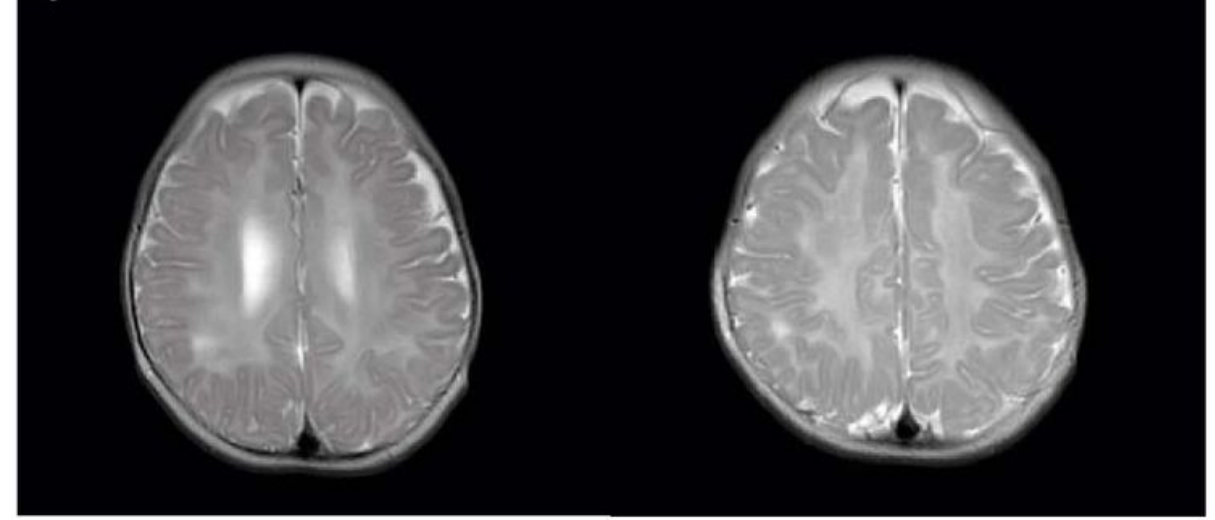

C

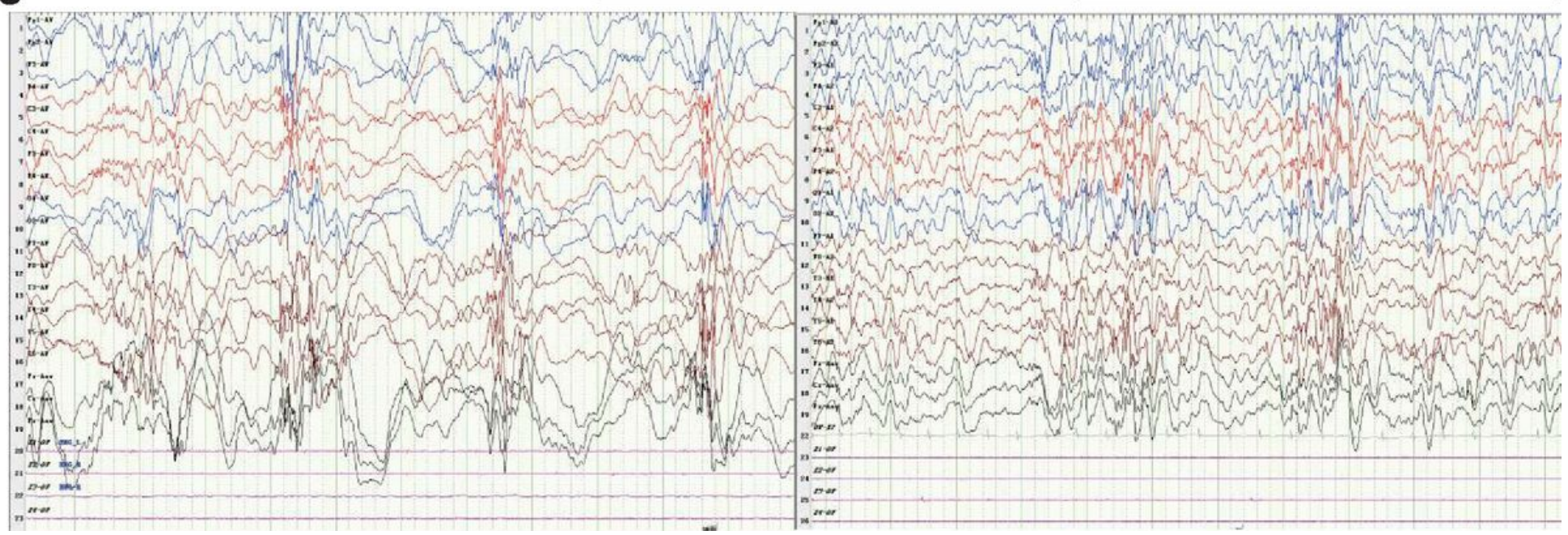

\section{Figure 1}

a Family pedigree indicating the variant genotypes. b Brain MRI of the affected individual. T2-weighted axial scan of the patient at 7 months showed delayed myelination and nonspecific loss of bilateral frontal parietal lobes white matter. c Interictal EEG at 7 months showed hypsarrhythmia consisting of bilateral high-amplitude irregular slow waves mixed with multiple focal spikes or poly spikes in the interictal period. 
Reference TTTCCCAATTCTTCÁTTCTGTCCTCCAAG

Proband TTTCCCAATTCTTC⿺̈丶TTCTGTCCTCCAAG

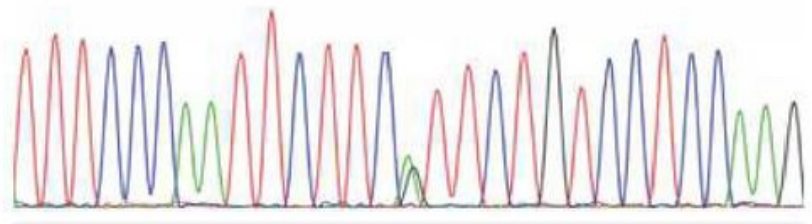

Father

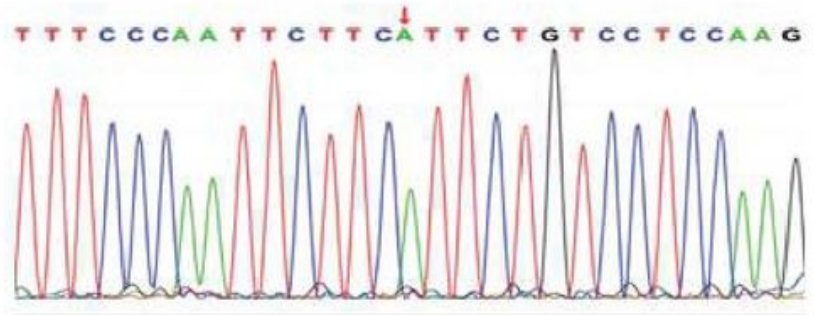

Mother

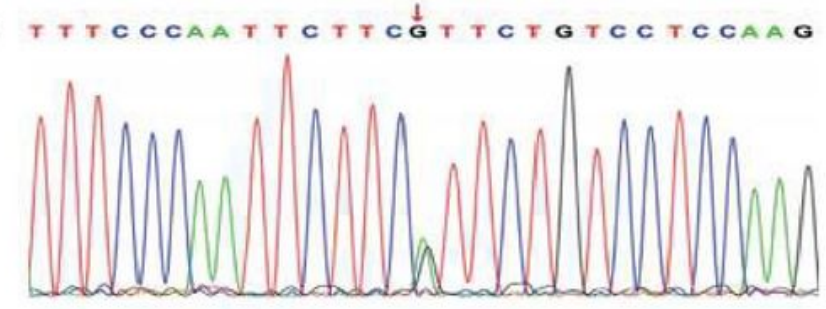

AP4M1: exon1 c. 19A>G (p. lle7Val)

b

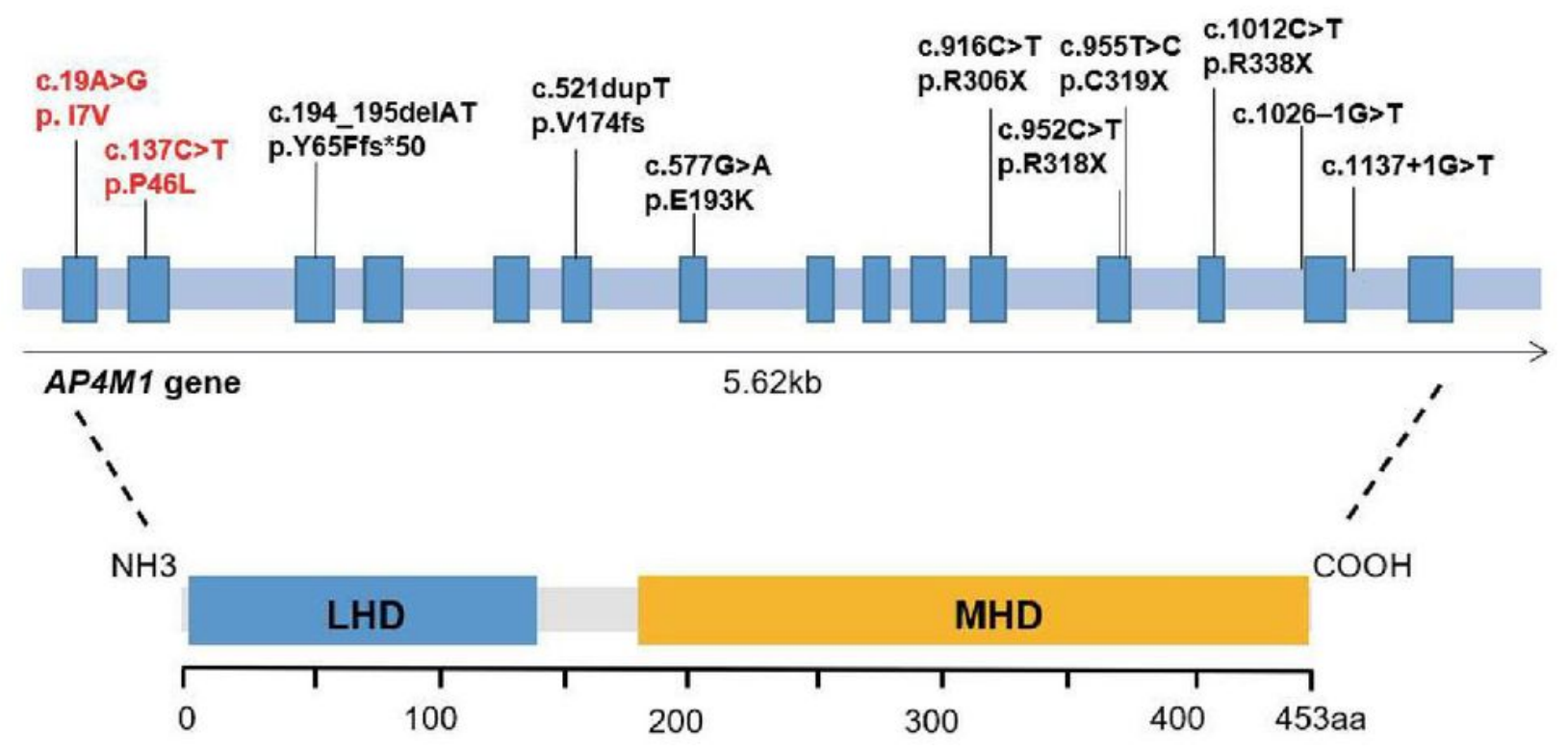

Figure 2

a Sanger sequencing electropherograms showing compound heterozygous mutations in $A P 4 M 1$ (c. 19A $>G$ and c. $137 \mathrm{C}>\mathrm{T}$ ). b. A schematic of the transcript and protein showing the reported eight variants in AP4M1 to date.

\section{Supplementary Files}


This is a list of supplementary files associated with this preprint. Click to download.

- AP4M1Table1.xlsx

- CAREchecklist.docx 